metabolites and suggested that $0 \cdot 1-4^{\circ}$ of the dose was excreted but they were unable to distinguish between prednisolone and its metabolites. Investigation ${ }^{9}{ }^{13}$ of the excretion of ${ }^{14} \mathrm{C}$-labelled prednisolone or prednisone administered per rectum showed that much of the radioactivity appeared ${ }^{913}$ in the urine.

There has been no published comparison of the therapeutic efficacy in colitis of prednisolone administered in equal doses by mouth and by enema. A controlled therapeutic trial ${ }^{14}$ showed only that $40 \mathrm{mg}$ of prednisolone given per rectum was more effective in acute colitis than $20 \mathrm{mg}$ given by mouth. ${ }^{14}$

Prednisolone probably does exert a local effect because patients are seen in whom an enema of inadequate volume successfully treats the distal colon, but proximal inflammation persists. ${ }^{7}$ Our results suggest that prednisolone in a dose of $20 \mathrm{mg}$ by retention enema may also exert a systemic effect.

We acknowledge the practical help given by Mrs Wendy May, SRN, during the study.

\section{References}

${ }^{1}$ Matts, S G F, Lancet, 1960, 1, 517.

${ }^{2}$ English, J, Chakraborty, J, and Marks, V, Annals of Clinical Biochemistry, 1974, $11,11$.

${ }^{3}$ Colburn, W A, and Buller, R H, Steroids, 1973, 21, 833.

4 Wilson, C G, et al, British fournal of Clinical Pharmacology, 1975, 2, 321.

${ }^{5}$ Pegg, P J, and Keene, P M, Steroids, 1969, 14, 705.

6 Baron, J H, Connell, A M, and Lennard-Jones, J E, British Medical fournal, 1964, $1,89$.

${ }^{7}$ Swarbrick, E T, Loose, H, and Lennard-Jones, J E, Proceedings of the Royal Society of Medicine, 1974, 67, 753.

${ }^{8}$ Wilson, C G, May, C S, and Paterson, J W, personal communication.

${ }^{9}$ Halvorsen, S, Myren, J, and Aakvaag, A, Scandinavian fournal of Gastroenterology, 1969, 4, 581.

${ }^{10}$ British Medical fournal, 1971, 3, 84.

11 Matts, S G F, et al, British Medical fournal, 1963, 2, 24

12 Wood, W A, Walters, G, and Matts, S G F, British Medical fournal, 1964, $2,1045$.

${ }^{13}$ Spencer, J A, Kirsner, J B, and Palmer, W L, Proceedings of the Society for Experimental Biology and Medicine, 1960, 103, 74.

14 Truelove, S C, British Medical fournal, 1960, 1, 464.

\title{
Do placebos alter sleep?
}

\section{KIRSTINE ADAM, LIISI ADAMSON, VLASTA BŘEZINOVÁ, IAN OSWALD}

British Medical fournal, 1976, 1, 195-196

\section{Summary}

Deliberate suggestion that an inert capsule was a sleeping pill was found not to influence subjective ratings of sleep quality or anxiety or the electrophysiologically recorded features of sleep in 10 volunteers aged 41-62 years.

\section{Introduction}

Efforts are being made to persuade doctors to prescribe fewer sleeping pills. It is often asked whether an inert substitute might be effective through suggestion alone. Kales et al compared the effect of placebo with that of no treatment in eight young men with complaints about their sleep and found no difference in objective measurements-delay to falling asleep, duration of sleep, or distribution of sleep stages - or in subjective ratings of sleep. Hartmann et $a l,,^{2} 3$ in two studies, also found no clear effects. Their proposed relationship between placebo administration and an increased amount of rapid-eye-movement (REM) sleep may have been an artefact of unbalanced design.

We here report the results of a further study in which 10 volunteers were given a placebo disguised as a sleeping pill.

\section{Patients and methods}

The 10 volunteers, six women and four men, were aged 41-62 (mean 57) years. This age and sex distribution is representative of patients who most often complain of inadequate sleep. They were asked to keep to a regular daily routine and to take no drugs or alcohol.

University Department of Psychiatry, Royal Edinburgh Hospital, Edinburgh EH10 5HF

KIRSTINE ADAM, BSC, research associate

LIISI ADAMSON, licentiate in medicine, research fellow

VLASTA BREZINOVA, MD, PHD, research psychiatrist

IAN OSWALD, MD, DSC, reader in psychiatry
The volunteers were given the following written statement: "You will be given a mild sleeping pill; it will help to make your sleep more restful without causing any hangover." An inert pink pill was given 30 minutes before lights-out on half of the recorded nights. The volunteers attended the laboratory in pairs, only one of them receiving the pill on any one night. The experiment was divided into two periods of two weeks separated by 21 weeks. During each period the volunteers attended for electrophysiological recording on eight nights, the first two serving for adaptation. Thus each person received the pill on six nights and nothing on another six nights, the order being balanced.

The electroencephalogram (EEG), eye movements, and submental muscle tone were recorded from 22.30 until 07.15 . The recordings were categorised ${ }^{4}$ by a scorer who was unaware of the experimental condition, and the sleep and wakefulness data then analysed for their mean accumulation in minutes after one hour, two hours, and so on up to seven hours of sleep.

Each evening the volunteers rated their average anxiety for the day, and each morning rated their sleep, using $10 \mathrm{~cm}$ visual analogue scales. The scales ranged from "terrible agitation" to "imperturbable tranquillity," and from "the worst" to "the best night imaginable." Correlated $t$ tests were used to compare the 60 placebo nights and 60

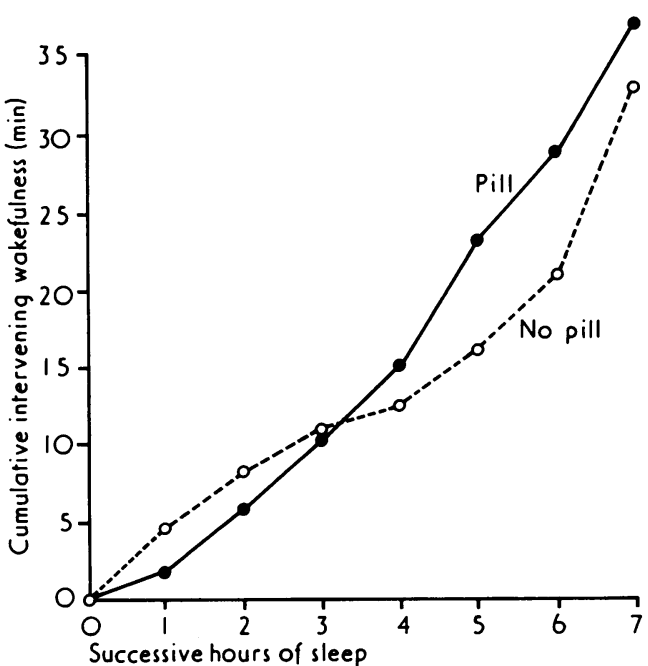

FIG 1-Mean cumulative minutes of wakefulness during night's sleep of 10 volunteers on pill nights and no-treatment nights $(t=0.90 ; \mathrm{DF}=9 ; \mathrm{NS})$. 


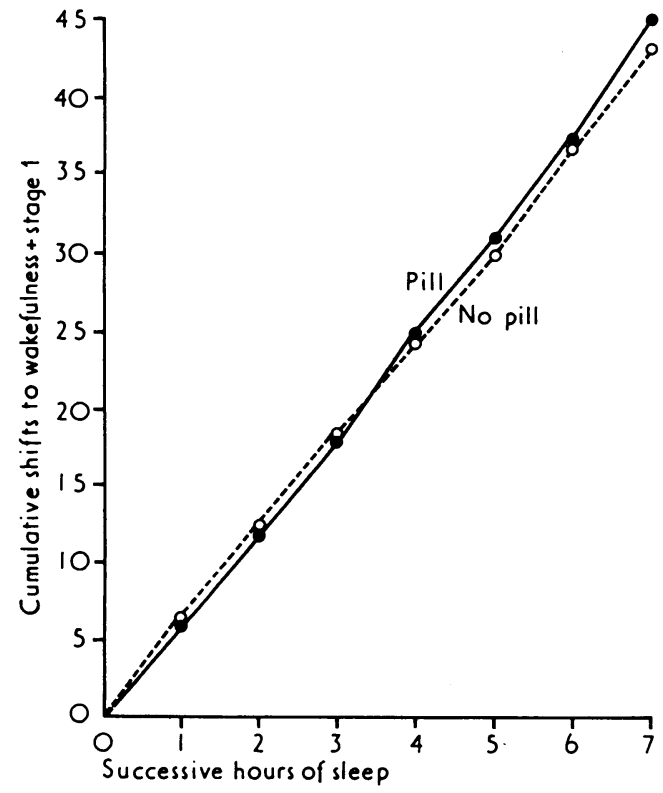

FIG 2-Mean combined numbers of times that sleep was disrupted by wakefulness and periods of drowsiness (stage 1 ) in the 10 volunteers on pill nights and no-treatment nights.

no-treatment nights using each person's mean score under each condition.

\section{Results}

The subjective ratings showed no change in sleep quality when the pill nights were compared with the no-treatment nights (mean scores ( \pm SE of mean) $45 \cdot 6 \pm 2.4 \mathrm{~mm} v 49 \cdot 2+3.3 \mathrm{~mm}$; NS). The volunteers knew when it was their turn to be given the placebo, but on the days when they were to take it at night their ratings of anxiety were not altered $(51.8 \pm 1.8 \mathrm{~mm} v 52.9 \pm 2.1 \mathrm{~mm}$; NS).

The electrophysiological recordings showed no significant differences between the 60 pill nights and the 60 no-treatment nights. This was true for the mean time it took to fall asleep (24.9 $\pm 3.9 \mathrm{~min}$ $v 21.9 \pm 4.2 \mathrm{~min}$; NS) and for the accumulation of wakefulness that intervened during the night's sleep or any of its parts (fig 1). The amounts of stage 1 (drowsiness), stage 2, stages 3 and 4, and REM sleep, total sleep duration, and REM sleep latency were similarly unaffected. The numbers of times that sleep was disrupted by waking or periods of drowsiness were combined and also found to be unaffected (fig 2).

\section{Discussion}

The absence of any difference between the subjective ratings under the two conditions was not a result of insensitivity of the method. The same 10 volunteers had taken part in a cross-over study of nitrazepam $5 \mathrm{mg}$ and a food drink. Their ratings showed a significant improvement in sleep quality for both substances, with a deterioration on withdrawal of the drug. ${ }^{5}$

In older people sleep is frequently broken by periods of wakefulness $^{6}$ 7 and is thus likely to show any influence of a sedative. In a study of a food drink (Horlicks) no significant effect was found on EEG-recorded sleep of young people, whereas the sleep of a group of older people similar to those studied here became significantly less broken than when a placebo pill was given. ${ }^{8}$ After our report on Horlicks it was proposed that suggestion could have been responsible. ${ }^{9}$ Our present studies offer no support for this, nor for any belief that when a placebo is prescribed for those of later middle age sleep will be substantially altered.

We thank Beecham Products Ltd for their help.

\section{References}

${ }^{1}$ Kales, J, et al, Clinical Pharmacology and Therapeutics, 1971, 12, 691.

2 Davis, D, and Hartmann, E, Sleep Research, 1973, 2, 51.

${ }^{3}$ Hartmann, E, and Cravens, J, Psychopharmacologia, 1973, 33, 153.

${ }^{4}$ Rechtschaffen, A, and Kales, A, (editors), Manual of Standardized Terminology, Techniques and Scoring System for Sleep Stages of Human Subjects. Washington, US Government Printing Office, 1968.

5 Adam, K, et al, Postgraduate Medical fournal, 1976, 52, 42.

6 Williams, R L, ot al, EEG of Human Sleep. New York, Wiley, 1974.

${ }^{7}$ Březinová, V, Electroencephalography and.Clinical Neurophysiology, 1975, 39, 273.

${ }^{8}$ Błezinová, V, and Oswald, I, British Medical fournal, 1972, 2, 431.

${ }^{9}$ Iversen, L L, and Mackay, A V P, British Medical fournal, 1972, 2, 766.

\section{SHORT REPORTS}

\section{Genetic diabetes not linked to the HLA locus}

Hereditary factors appear to be of great importance in the aetiology of maturity-onset diabetes. In a series of diabetic identical twins all the pairs in which the index twin developed diabetes over 45 were concordant - that is, the co-twins were also diabetic-and nearly half had a diabetic parent. ${ }^{1}$ As most of the twins had lived apart for most of their adult lives, diabetic concordance is more likely to have been due to genetic than environmental causes.

By contrast, the genetic contribution to classical juvenile-onset diabetes (JOD) is much less clear. In the twin study ${ }^{1}$ half the pairs in which diabetes was diagnosed in the index twin under 45 were discordant (only one twin affected), and remained so on repeated glucose tolerance testing, and few had a family history of diabetes. In these pairs the diabetes must be largely of environmental origin. This is consistent with the view that viruses may damage the pancreatic islets.

Studies of histocompatibility antigens in patients with JOD suggest a possible mechanism for genetic susceptibility to infections. The frequency of the antigens HLA-8 and W15 is increased in insulindependent but not in maturity-onset diabetics. ${ }^{2}{ }^{3}$ Furthermore, in families in which two or more sibs have JOD there is a highly significant increase in the number with one or both HLA haplotypes identical. ${ }^{4}$ Both these findings suggest the presence of an important gene predisposing to this type of diabetes near the HLA locus on the 6th chromosome.

There is one kind of diabetes-maturity-onset diabetes of young people (MODY) - of which 3 families have been described from this department ${ }^{5}$ which appears to be purely genetic in origin. Diabetes appears in early life; is and remains mild, insulin seldom, if ever, being needed; and complications are conspicuously rare. The evidence for a dominant pattern of inheritance is overwhelming-three successive generations affected in direct line, all (or nearly all) cases having an affected parent and half of the offspring of affected individuals being themselves affected. It was of interest to discover whether this type of diabetes whose inheritance is clearly distinct from that in other types of the disease (insofar as we understand it) was also associated with specific HLA types.

We have HLA-typed 13 diabetic and nine non-diabetic members of these families. All the non-diabetics have had oral glucose tolerance tests with results in the normal range. Three of 13 diabetics $(23 \%)$ and two of the nine non-diabetics $(22 \%)$ were HLA-8 positive, both figures being the same as the control frequency for this antigen $(20-31 \%)^{4}$; in classical JOD the frequency of this antigen is approximately twice normal. So far, the W 15 antigen has not been found in these families (control frequency $5-14 \%$ ).

The figure illustrates the pattern of inheritance of HLA haplotypes 